\title{
Evaluation of Antioxidant Activity and Membrane Stability of Three Unani Medicines Preparation in Bangladesh
}

\section{SAZAUL MORSHED SAZIB ${ }^{1}$, SADIA AFROZ², TARIQUL ISLAM ${ }^{3}$, ABDULLAH AL RAGIB $^{\star 2,4}$, MUHAMMAD ZUKAUL ISLAM ${ }^{5}$ and ABDULLAH AL MAHMUD ${ }^{6}$}

${ }^{1}$ Department of Pharmacy, Noakhali Science and Technology University, Noakhali-3814, Bangladesh.

${ }^{2}$ Department of Applied Chemistry and Chemical Engineering, Noakhali Science and Technology

University, Noakhali-3814, Bangladesh.

${ }^{3}$ Department of Pharmaceutical Technology, International Islamic University Malaysia, 25200 Kuantan,

Pahang, Malaysia.

${ }^{4}$ School of Chemical Engineering and Technology, Tianjin University, Tianjin 300350, China.

${ }^{5}$ Department of Chemistry, Bangladesh University of Engineering and Technology, Dhaka-1000,

Bangladesh.

${ }^{6}$ Department of Pharmacy, Manarat International University, Dhaka-1212, Bangladesh.

${ }^{*}$ Corresponding author E-mail: ragibnstu@gmail.com

http://dx.doi.org/10.13005/ojc/360117

(Received: January 01, 2020; Accepted: February 20, 2020)

\begin{abstract}
A comparative pharmacological study of three different Unani medicines is performed, trade named Safi, Musaffi and Hemosaf used for blood purification. In which, different concentration of the syrups were evaluated for its possible membrane stabilizing and antioxidant activity. Gallic acid and ascorbic acid were used as a standard for antioxidant activity. Acetyl salicylic acid (ASA) $(0.10 \mathrm{mg} /$ $\mathrm{mL}$ ) was also used as standard drug for membrane stability. The amount of total phenolic content for Safi, Musaffi and Hemosaf was subsequently $542.2 \mathrm{mg}, 444.27 \mathrm{mg}$ and $432.20 \mathrm{mg}$ of GAE/ $\mathrm{mg}$ of sample solution. DPPH radical scavenging activities of three Samples were increased with the increasing concentration. Maximum inhibition (radical scavenging) $85.96 \%$ for Hemosaf was observed at $100 \mu \mathrm{g} / \mathrm{mL}$ concentration with $\mathrm{IC}_{50}$ of $1.91 \mu \mathrm{g} / \mathrm{mL}$ compared to standard (ascorbic acid) inhibition $95.86 \%$ with $\mathrm{IC}_{50}$ of $1.93 \mu \mathrm{g} / \mathrm{mL}$. Among all the syrup fractions, at $8.0 \mathrm{mg} / \mathrm{mL}$ concentration maximum effect with a value of $50.24 \%, 47.70 \%$ and $34.85 \%$ hindrance of hemolysis of red blood cell (RBC) caused by hypotonic solution of Safi, Musaffi and Hemosaf respectively as compared to $67.01 \%$ showed by standard acetyl salicylic acid (ASA). Finally, it might be a source of antioxidant activity and possess good membrane stability effects.
\end{abstract}

Keywords: Unani medicine, Antioxidant activity, Radical scavenger, Membrane stabilization.

\section{INTRODUCTION}

Thousands of years ago from the history of human evaluation the use of medicinal plants by human beings to treat diverse diseases ${ }^{1}$. From the early stage of human civilization, natural

This is an Open Access article licensed under a Creative Commons license: Attribution 4.0 International (CC- BY). Published by Oriental Scientific Publishing Company @ 2018

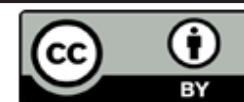


products and medicinal plants which are used by indigenous people as, traditional medicine are of great importance to discover a number of modern drugs ${ }^{2}$. To early humans the use of natural and biomedicines has presented a great challenge and later by the development of outstanding therapeutic tools and technology they were able to develop knowledge about edible materials, phytomedicine, biomedicine or natural medicines ${ }^{3}$. Traditional or complementary medicine gives advantages not only in the field of exploring pharmacological, pharmacokinetic and toxicological features over other forms of medicine but also gives favorable position in such areas of discovery of drug candidates and examining drug-like activity2,4. In addition, serious side-effects and high cost of number of modern medicines is a great solicitous in public health and for this today people like to depend on medicinal plants as a source for discovery of newer unani or phyto-based drugs with low cost and less side-effects ${ }^{5}$. Scientific report shows that not less than $80 \%$ of the world's population still depends on phytotherapy and $64 \%$ of the world populations in both urban and rural areas totally tend to use traditional medicinal plants to protect and cure their health from various dangerous diseases ${ }^{6,7}$. Chemical constituents and medicinal uses of 449 medicinal plants growing and available in South Asia especially Bangladesh are listed. Because of the availability of these indigenous medicinal plants they are extensively used in the preparation of unani and ayurvedic medicines in South Asia like Bangladesh, India, Nepal, Bhutan etc. But the fact is that almost all of them are lacking proper scientific evaluation of their therapeutic uses. So, time demands standard pharmacological protocol and phytochemical analysis to establish scientific evidence of the efficiency of these preparations in pharmacological use ${ }^{8}$.

\section{MATERIALS AND METHODS}

\section{Reagents, Chemicals and Instruments}

Folin-Ciocaltu reagent, gallic acid, sodium carbonate $(7.5 \% \mathrm{w} / \mathrm{v})$, distilled water, syrup solution (3 unani samples), DPPH (1,1-diphenyl-2-picrylhydrazyl), standard acetyl salicylic acid (ASA), human red blood cell (RBC), anticoagulant EDTA, phosphate buffer $(\mathrm{pH} 7)$, sodium chloride, isotonic solution, glass ware, stirring bar, UV spectrophotometer, weighing machine etc. All chemicals are purchased from Merck, Germany.

\section{Antioxidant activity Total Phenolic content}

To determine the total phenolic content of all the unani preparations Folin-Ciocalteu reagent was used ${ }^{9}$. Folin-Ciocalteu reagent produced complex blue color which is a combination of phosphomolybdate and phosphotungstate reduced the polyphenols containing samples ${ }^{10}$. A gallic acid calibration curve is used to estimate the phenolic concentration of extracts sample. So it is important to prepare a calibration curve and for this firstly we need to prepare $0.5 \mathrm{~mL}$ aliquots. The concentration should be maintained within a range which is $100 \mu \mathrm{g} / \mathrm{mL}$ to $6.25 \mu \mathrm{g} / \mathrm{mL}$ gallic acid solutions and then $2.5 \mathrm{~mL}$ of diluted (at a ratio of $1: 10$ with water) Folin-Ciocalteu reagent were mixed. Then, $7.5 \%$ $(\mathrm{w} / \mathrm{v})$ sodium carbonate $(2.0 \mathrm{~mL})$ was added to neutralize the mixture. After that $20 \mathrm{~min}$. incubation is maintained for color progression at $25^{\circ} \mathrm{C}$ and total phenolic content of the sample solution was estimated at $760 \mathrm{~nm}$ in contradiction of reagent blank sample. The total phenolic contents of extract sample were expressed as mg of gallic acid equivalent weight (GAE) and absorbance vs. concentration curve was constructed which showed a Liner relationship.

\section{Assay for DPPH activity}

The stable DPPH radical-scavenging activity was measured by Following Gupta's design with slightly modification ${ }^{11,12}$. In this method stock solutions $(1 \mathrm{mg} / \mathrm{mL})$ of each sample were prepared in respective and universal solvent (water). To prepare stock solutions serial dilutions were carried out and having the range of $100 \mu \mathrm{g} / \mathrm{mL}$ to $12.5 \mu \mathrm{g} / \mathrm{mL}$ concentration. In this investigation, sample solution $(2 \mathrm{~mL})$ at various concentration in which $2 \mathrm{~mL}$ of $0.2 \mathrm{mM}$ methanolic DPPH was added and in the mean time it was stirred strenuously (15 seconds). After that at room temperature the solution must be kept at dark place because of reaction condition in which the solutions were allowed to stand approximately 30 minutes. After that absorbance was performed at $517 \mathrm{~nm}$ against a reagent blank ${ }^{13}$. From the graph the $\mathrm{IC}_{50}$ value of each sample was estimated by non-linear regression. Ascorbic acid was used as positive control standard.

\section{Membrane Stabilizing}

In vitro membrane stabilizing screening of was performed by following the methods developed by Sikder et al., ${ }^{14}$.

\section{Hypotonic Solution-Induced Haemolysis}

Suspension of RBC used as stock test sample that was collected from male human 
under standard condition. Then, the hypotonic solution were used to perform the experiment. In addition, isotonic solution (154 $\mathrm{mM} \mathrm{NaCl})$ and sodium phosphate buffer ( $\mathrm{pH} 7.4 \& 10 \mathrm{mM})$ were used to wash the blood three times by centrifugation in which time limit was $10 \mathrm{~min}$. at $3000 \mathrm{~g}$ (RPM). After that RBC suspension was finally collected as a stock and EDTA was used for the prevention of clotting. So for the evaluation of membrane stabilizing, the stock solution, 5 $\mathrm{mL}$ of hypotonic solution $(50 \mathrm{mM} \mathrm{NaCl})$ in 10 $\mathrm{mM}$ sodium phosphate buffer saline $(\mathrm{pH} 7.4)$, 3 different unani medicine Safi, Musaffi and Hemosaf $(1.0 \mathrm{mg} / \mathrm{mL}$ ) and ASA (Acetyl Salicylic Acid) was used. The acetyl salicylic acid was used as a reference standard $(0.1 \mathrm{mg} / \mathrm{mL})$. Then incubation was done for the duration of $10 \mathrm{~min}$. at room temperature and also at the same time centrifugation was also performed for $10 \mathrm{~min}$. (RPM 300). UV spectrophotometer (Shimadzu) measured the absorbance of the unani sample at $540 \mathrm{~nm}$. Inhibition percentage of membrane stabilization was determined by standard protocol and shown in Table $3^{15,16}$.

\section{EXPERIMENTAL}

Total phenolic content determination and DPPH radical scavenging activity of different unani samples for antioxidant activity identification and effect of extract of Safi, Musaffi and Hemosaf on hypotonic solution-induced haemolysis of erythrocyte membrane for Membrane Stabilizing activity identification have been described.

Table 1: Determination of Total Phenolic Content of 3 Unani syrups ( 3 samples prepared from one syrup)

\begin{tabular}{lcccc}
\hline $\begin{array}{l}\text { Syrup } \\
\text { Name }\end{array}$ & $\begin{array}{c}\text { Sample } \\
\text { preparation }\end{array}$ & Absorbance & $\begin{array}{c}\text { Average } \\
\text { Absorbance }\end{array}$ & $\begin{array}{c}\text { Total Phenolic } \\
\text { Content (mg of } \\
\text { GAE/mg) } \\
\text { of Sample }\end{array}$ \\
\hline Safi & 1 & 1.898 & & \\
& 2 & 1.732 & 1.68 & 542.2 \\
& 3 & 1.411 & & \\
Musaffi & 1 & 1.596 & & 444.27 \\
& 2 & 1.329 & 1.396 & \\
& 3 & 1.264 & & 432.2 \\
Hemosaf & 1 & 1.642 & & \\
& 2 & 1.322 & 1.361 & \\
& 3 & 1.119 & & \\
\hline
\end{tabular}

Values were calculated as $10 \mathrm{mg}$ of the syrup and are expressed as mean $(n=3)$ and the absorbance was measured 3 times for each of samples.

\section{Antioxidant activity}

Total phenolic content determination

In this method, we depend and continue our investigation based on the absorbance values of different sample solutions by the colorimetric analysis in which the total phenolic content of different samples was determined and gallic acid equivalents was used to compare the sample as a standard solution.

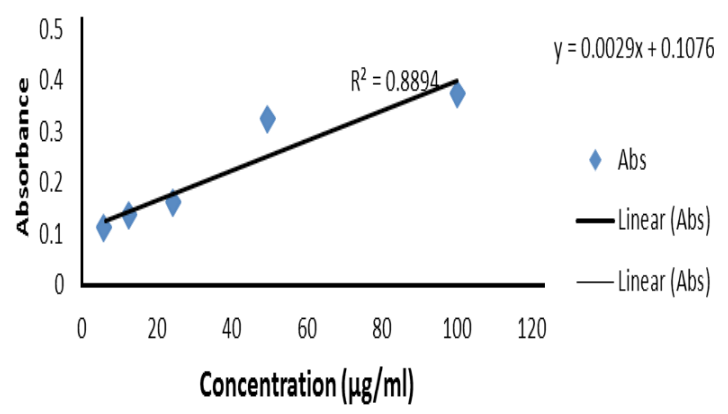

Fig. 1. Total Phenolic Content of Gallic Acid (Standard)

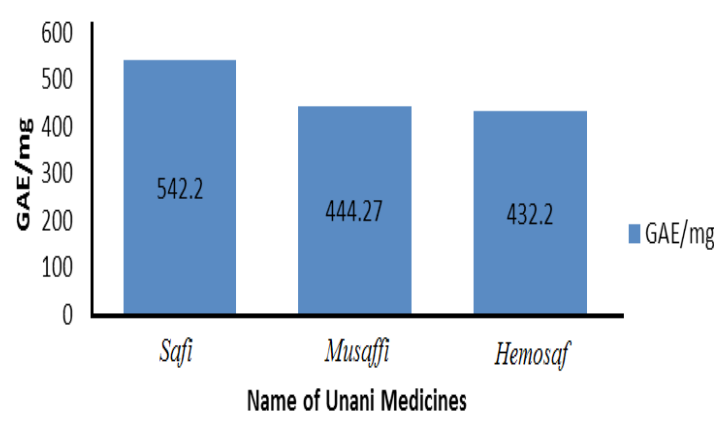

Fig. 2. Total Phenolic Content of 3 Unani syrups

Figure 3 is graphical representing the DPPH free radical scavenging activity of different concentration of 3 unani Samples.

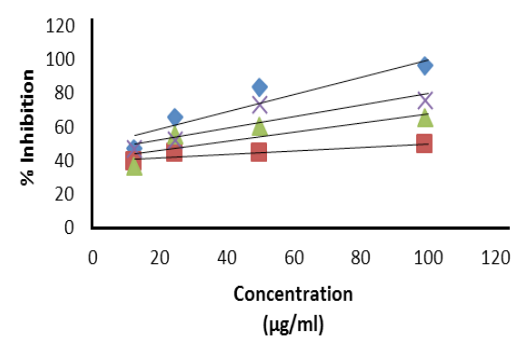

$$
\begin{aligned}
& y=0.5147 x+48.552 \\
& \text { - Standard } \\
& \text { - Safi } \\
& \triangle \text { Musaffi } \\
& \times \text { Hemosaf } \\
& \text { _ Linear (Standard) } \\
& \text { — Linear (Safi) } \\
& \text { — Linear (Musaffi) }
\end{aligned}
$$

Fig. 3. DPPH radical scavenging activity of different unani samples

The concentration has a prominent effect on scavenging activity, in a proportional way concentration increase the DPPH radical activity of 3 samples. For instance, maximum inhibition 85.96 
for Hemosaf was spotted at $100 \mu \mathrm{g} / \mathrm{mL}$ and $\mathrm{IC}_{50}$ $(\mu \mathrm{g} / \mathrm{mL})$ was measured 1.91 From the standard curve showed that when the concentration was
$100 \mu \mathrm{g} / \mathrm{mL}$, the inhibition is maximum which is $95.85 \%$ and $50 \%$ inhibition (radical scavenging) at $1.93 \mu \mathrm{g} / \mathrm{mL}$.

Table 2: Comparative DPPH radical scavenging activity of 3 Samples and standards of Ascorbic Acid

\begin{tabular}{|c|c|c|c|c|c|c|c|c|}
\hline \multirow{3}{*}{$\begin{array}{l}\text { Concentration }(\mu \mathrm{g} / \mathrm{ml}) \\
12.5\end{array}$} & \multicolumn{8}{|c|}{$\%$ Standard and inhibition (in \%) of different samples } \\
\hline & \multicolumn{2}{|c|}{ Safi } & \multicolumn{2}{|c|}{ Musaffi } & \multicolumn{2}{|c|}{ Hemosaf } & \multicolumn{2}{|c|}{ Ascorbic acid (Standard) } \\
\hline & 39.53 & $\mathrm{IC}_{50}(\mu \mathrm{g} / \mathrm{ml})$ & 36.21 & $\mathrm{IC}_{50}(\mu \mathrm{g} / \mathrm{ml})$ & 45.84 & $\mathrm{IC}_{50}(\mu \mathrm{g} / \mathrm{ml})$ & 47.42 & $\mathrm{IC}_{50}(\mu \mathrm{g} / \mathrm{ml})$ \\
\hline 25 & 44.35 & 99.45 & 53.65 & 33.17 & 51.99 & 1.91 & 64.42 & 1.93 \\
\hline 50 & 45.34 & & 60.13 & & 72.42 & & 83.03 & \\
\hline 100 & 49.66 & & 64.78 & & 85.96 & & 95.85 & \\
\hline
\end{tabular}

\section{Membrane Stabilizing Activity}

DifferentUnani preparation samples subjected to analyze for membrane stabilizing activities were expressed in statistically (Table 2 ). In hypotonic solution activated conditions, the samples were observed for inhibition of lysis for erythrocyte membrane within the range of $6.86-67.01 \%$. The samples exhibited optimum inhibition of $50.24 \%$ hemolysis of RBC respectively as compared to $67.01 \%$ showed by acetyl salicylic acid, whereas the minimum inhibition capability was observed at $2.00 \mathrm{mg} / \mathrm{mL}$.

Table 3: Effect of extract of Safi, Musaffi and Hemosaf on hypotonic solution-induced haemolysis of erythrocyte membrane

\begin{tabular}{|c|c|c|c|}
\hline Treatment & $\begin{array}{l}\text { Concentration } \\
\qquad(\mathrm{mg} / \mathrm{mL})\end{array}$ & Optical density & $\begin{array}{c}\% \text { inhibition of } \\
\text { haemolysis }\end{array}$ \\
\hline \multirow[t]{2}{*}{ Control } & 1 & 3.698 & - \\
\hline & 2 & 3.444 & 6.86 \\
\hline \multirow[t]{4}{*}{ Safi } & 4 & 2.718 & 26.5 \\
\hline & 6 & 2.284 & 38.23 \\
\hline & 8 & 1.84 & 50.24 \\
\hline & 2 & 2.839 & 23.22 \\
\hline \multirow[t]{4}{*}{ Musaffi } & 4 & 2.413 & 34.74 \\
\hline & 6 & 2.376 & 35.74 \\
\hline & 8 & 1.934 & 47.7 \\
\hline & 2 & 3.244 & 12.27 \\
\hline \multirow[t]{3}{*}{ Hemosaf } & 4 & 2.758 & 25.41 \\
\hline & 6 & 2.654 & 28.23 \\
\hline & 8 & 2.409 & 34.85 \\
\hline Acetyl salicylic acid & 0.1 & 1.22 & 67.01 \\
\hline
\end{tabular}

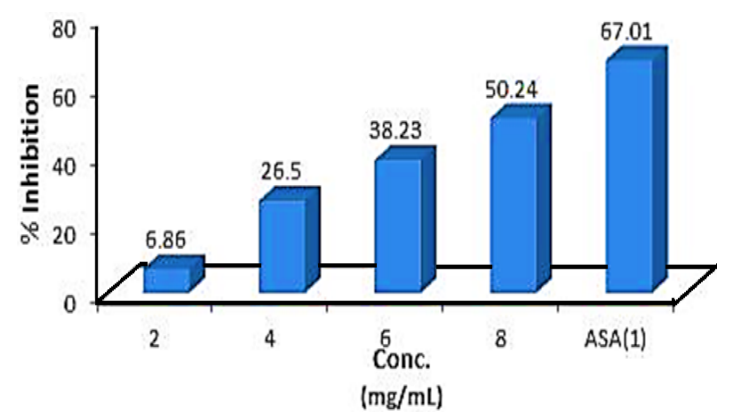

Fig. 4. Inhibition of haemolysis by Safi

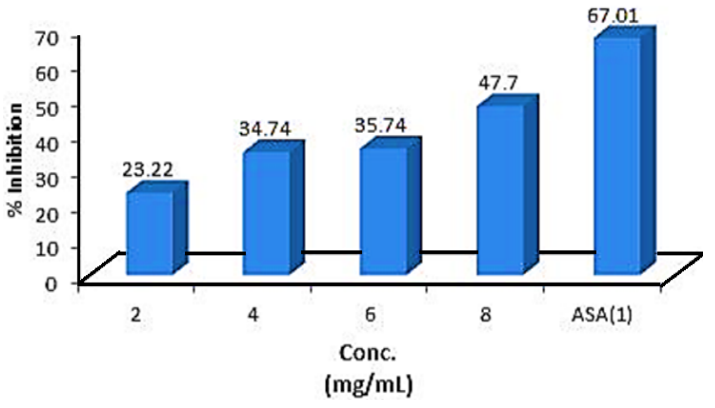

Fig. 5. Inhibition of haemolysis by Musaffi

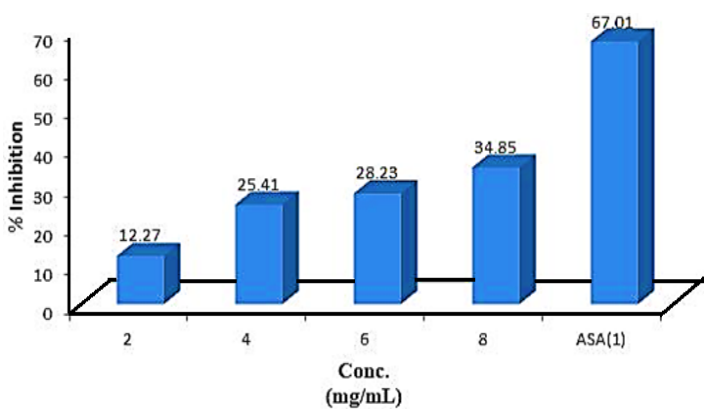

Fig. 6. Inhibition of haemolysis by Hemosaf

\section{DISCUSSION}

The amount of total phenolic content for Safi, Musaffi and Hemosaf represented in Fig. 2 which revealed that the samples have important phenolic property which is further needed to research broadly. In this investigation, the samples from unani preparations presented modest antioxidant properties with an $\mathrm{IC}_{50}$ compared to the standard values of a drug commonly used. Antioxidant activity of these different samples was found to increase with the increasing concentration compared to the standard which is also relevant. Lysis of the red blood cell membranes accompanied by the oxidation when accepted to harmful substances such as hypotonic medium through lysis of hemoglobin that Causes 
to release inflammatory agent ${ }^{17}$. To determine the anti-inflammatory activity of the sample preparations, it is important to consider their potentiality of inhibition ${ }^{16,17}$. Our current investigation deals with the methanolic samples of the unani preparations which showed potent RBC membrane stabilization activity. So it is easily determined from the gallic acid equivalent in total phenolic content graph that Safi and Hemosaf subsequently contain highest and lowest amount of phenolic content and they reversely exhibit anti-oxidant activity. From Membrane Stabilizing Activity test it can be conclude as, "although Musaffi has large membrane stabilizing capacity than Safiand Hemosaf at low concentration but Hemosaf has the regular stabilizing activity in each concentration".

\section{CONCLUSION}

In developing countries most of the poor population has to depend on the indigenous systems for the maintenance of their health. This study inspires the increasing use of unani medicines day by day. But the effectiveness of these drugs is not clearly exposed scientifically where most of which are distributed in a raw state and below standard form to the people. The use of such drugs may dangerous and threatens for public health. Thus the analysis of these drugs for exploring its chemical properties and their biological investigation is the present need for standardization of unani medication system. In South Asian less developing country like Bangladesh has to spend a lot of money for importing raw materials and semi or partially processed pharmaceutical drugs of plant origins from other countries and this trend is growing upwards day by day. This huge amount of money would be saved if the use of native medicinal plants or their raw products which are used by the unani and herbal drugs satisfy the public needs and this study is also done for this sense to understand the actual quality of popular unani medicines which is related to public health.

\section{ACKNOWLEDGEMENT}

The authors are highly acknowledged all the provided facilities; specially laboratory support by the Department of Pharmacy, Noakhali Science and Technology University.

\section{Conflicts of Interest}

The authors declare that they have no competing interests.

\section{REFERENCES}

1. Rahmatullah, M.; Hasan, A.; Parvin, W., Moniruzzaman, M.; Khatun, A.; Khatun, Z.; Jahan, R. African J. Tradit. Complement. Altern. Med., 2012, 9, 350-359.

2. Yuan, H.; Ma, Q.; Ye, L.; Piao, G. Mol., 2016, 21, 559-576.

3. Hassan, M.; Ragib, A.; Hossain, M.T; Sazib, S.M.; Islam, M. Z. Nor. Am. Aca. Res., 2019, 3, 1-14.

4. Che, C.T.; George, V.; Ijinu, T.P.; Pushpangadan, P.; Andrae-Marobela, K. Pharmacogn., 2017, 15-30.

5. Kaya, H.O. J. African Stud., 2017, 31, Supplement 1.

6. Raju, G.S.; Moghal, M.M.R.; Dewan, S.M.R.; Amin, M.N.; Billah, M. M. Avicenna J. Phytomed., 2013, 3, 313-320.

7. Ekor, M. Front. Pharmacol., 2014, 4, 177-186.

8. Astutik S.; Pretzsch J,; Kimengsi, J.N. Sustainability., 2019, 11, 5483-5516

9. Agbor, G.A.; Vinson, J.A.; Donnelly, P.E. Int. J. Food Sci. Nutr. Diet., 2014, 3, 147-156.
10. Blainski, A., Lopes, G.; de Mello, J. Mol., 2013, 18, 6852-6865.

11. Gupta, M.; Mazumeder, U.K.; Sivahkumar, T.; Vamis, M.; Karki, S.; Sambathkumar, R. Elsevier Inc., 2003, 7, 15-30.

12. Gupta, M.; Mazumder, U.; Gomathi, P. Asian J. Plant Sci., 2007, 6, 533-537.

13. Majumder, M.S.; Hossain, D.M.S.; Amin, M.N.; Moghal, M.M.R.; Banik, S.; Hossain, M.M. World J. Pharm. Pharm. Sci., 2014, 3, 58-72.

14. Sikder, M.A.; Kaiser, M.A.; Rashid, M.A.; Millat, M.S.; Sultan, A. J. Pharmacol. Phy-tochem., 2012, 1, 45-50.

15. Shinde, U.A.; Phadke, A.S.; Nair, A.M.; Mugantiwar, A.A.; Dikshit, V.J.; Saraf, V.O. Fitoterapia., 1999, 70, 251-257.

16. Feirrali, M.; Signormi, C.; Ciccolili, L.; Comporti, M. Biochem. J., 1992, 28, 5295-5301.

17. Mounnissamy, V.M.; Kavimani, S.; Balu, V.; Quine, S.D. Iranian J. Pharmacol. Therap., 2007, 6, 235-237. 